\title{
DIREITOS SEXUAIS DE CRIANÇAS E ADOLESCENTES: AVANÇOS E ENTRAVES
}

\author{
Cintia de Sousa Carvalho* \\ Elisângela Ribeiro da Silva** \\ Solange Jobim e Souza*** \\ Raquel Gonçalves Salgado ${ }^{* * * *}$
}

\section{Resumo}

O tenso encontro entre infância/adolescência e sexualidade é questão fundamental do presente trabalho. Neste sentido, pretende-se analisar de que modo instituiçóes de atendimento que lidam com o público infanto-juvenil se posicionam frente à garantia dos direitos sexuais e reprodutivos destes sujeitos. As reflexões apresentadas foram construídas a partir de um recorte de situaçóes vivenciadas em duas pesquisas de campo, realizadas em instituiçôes de educação e saúde. Os excertos analisados sugerem que há uma dificuldade em se garantir, nas práticas institucionais, os direitos sexuais de crianças e adolescentes (e reprodutivos destes últimos), visto que há uma indiferenciação entre sexualidade e genitalidade, representação esta que afeta a compreensão dos limites entre autonomia e proteçáo. Compreende-se que para que se possa efetivar a garantia destes direitos é necessário que crianças e adolescentes participem desta construção teórico-prática.

Palavras-chave: direitos sexuais; infância; adolescência; sexualidade; autonomia.

\section{Abstract}

SEXUAL RIGHTS OF CHILDREN AND ADOLESCENTS: ADVANCES AND OBSTACLES

This study is aimed to carry out discussions over the tense encounter between childhood/ adolescence and sexuality. The goal is to analyze in what way supporting care institutions for tee-

* Departamento de Psicologia, PUC-Rio, Rio de Janeiro, RJ, Brasil. E-mail: cintiapsicologia_51@hotmail.com.

** Departamento de Psicologia, PUC-Rio, Rio de Janeiro, RJ, Brasil. E-mail: elisribeiros@ gmail.com.

*** Departamento de Psicologia, PUC-Rio, Rio de Janeiro, RJ, Brasil. E-mail: soljobim@ puc-rio.br.

**** Universidade Federal de Mato Grosso, Rondonópolis, MT, Brasil. E-mail: ramidan@terra.com.br. 
nagers assure them their sexual and reproductive rights. The reflections we bring to attention were built from two field researches, conducted in education and health institutions. The analyzed data suggests that, in practical terms, it is difficult to ensure sexual rights of children and sexual and reproductive rights of teenagers, given that there is no differentiation between sexuality and genitality. This representation affects the understanding of the limits between autonomy and protection. It is understood that, to ensure these rights effectively, children and teenagers should participate in building a theoretic-practical concept.

Keywords: sexual rights; childhood; adolescence; sexuality; autonomy.

\section{Introdução}

A sexualidade é inegavelmente um elemento da experiência humana. Assim sendo, o que impede que ela tenha seu próprio lugar, sua própria expressão no espectro dos diretos humanos? Sumit Baudh

A dimensão da sexualidade como elemento constituidor da condição humana apresenta-se, no campo das reflexôes sociais mais amplas, como uma premissa relativamente aceita (Cornwall \& Jolly, 2008). Entretanto, esse axioma se sustenta, por um lado, na complementaridade entre homens e mulheres, logo, na heterossexualização das relaçôes e práticas; e, por outro, numa sexualidade articulada a expectativas etárias. Ainda que haja um acordo social no sentido de conceber a sexualidade como elemento que faz parte da constituição humana, sua presença é apenas bem-vinda no momento da vida em que a genitália se apresenta biologicamente desenvolvida para exercer a prática sexual. Percebe-se, portanto, uma normatização desenvolvimentista que se endereça à construção de uma inteligibilidade acerca da sexualidade humana. Com base em critérios reconhecidos socialmente como "verdades científicas", cria-se uma legitimidade para se expurgar do universo infanto-juvenil a possibilidade de experiências que envolvam a dimensão sexual.

O tenso encontro entre infância e sexualidade acima descrito foi objeto de análise de Foucault (2001), ao discorrer sobre as anormalidades. De acordo com o autor, a criança "masturbadora" ou "onanista", que data da passagem do século XVIII para o século XIX, deveria ser responsabilidade da família burguesa, posto que tal prática era considera criminosa: "o segredo universal, o segredo compartilhado por todo mundo, mas que ninguém comunica a ninguém” (Foucault, 2001, p. 74). A família deveria velar por este comportamento, na tentativa de neutralizá-lo, pois seria este "exercício inapropriado", de acordo com o ideário 
médico burguês, responsável por desencadear patologias mentais/físicas e vícios morais. Percebe-se que o dispositivo médico e familiar são acessados no sentido de legitimar uma infância destituída de qualquer diálogo com a sexualidade.

É nessa mesma época que a ideia de infância se consagra na sociedade ocidental moderna e com ela elege-se a sexualidade como o grande divisor de águas entre os universos infantil e adulto (Ariès, 1981). Como mal a ser expurgado da vida das crianças, a sexualidade passa a ser perseguida e proibida por moralistas e confessores em nome da preservação da inocência infantil, atributo que institui a infância na modernidade. Nessa lógica, a criança só é inocente porque está afastada do sexo, experiência possível e permitida apenas para a vida adulta. Por meio das penitências religiosas, dos tratados de boas maneiras e da literatura infantil, a moral burguesa ensina as crianças a sentirem culpa por seus desejos, ideias e práticas sexuais, traduzindo-se em valor inabalável, que constitui os sujeitos, crianças e adultos, e demarca suas relaçóes com o próprio corpo e com o mundo.

Ainda que a sexualidade dos adolescentes, em contraponto ao universo infantil, seja compreendida a partir de discursos científicos que legitimam este momento da vida como precursor da experiência sexual adulta, algumas controvérsias fomentam o debate sobre os direitos sexuais nesta etapa da vida. Os adolescentes são compreendidos como pertencendo a um momento de passagem, ou seja, de transição da vida infantil para a vida adulta. A adolescência é considerada uma fase "conturbada", principalmente pela irrupção das produçóes hormonais. Embora os adolescentes sejam biologicamente aptos para diversas práticas, são considerados, muitas vezes, como incapazes ou irresponsáveis, do ponto de vista do amadurecimento biopsicológico. Deste modo, irrompem diversos discursos tutelares, que instituem os "perigos" da sexualidade adolescente, compreendida como uma prática negativa e precoce, podendo ocorrer "transmissão de patologias" e "gravidez indesejada" (Heilborn, 2006).

Neste sentido, percebe-se que a sexualidade infanto-juvenil, por vias distintas, é objeto de perseguição disciplinar. Faz-se, portanto, necessário compreender de que modo os discursos de poder instituíram este panorama que se desmembrou em práticas de controle. A questão é indagar sobre os efeitos e interesses que estão presentes no cotidiano das práticas sociais, quando estas práticas de controle tentam impedir a vivência da sexualidade como experiência fundamental em diferentes momentos da vida. Este artigo busca analisar de que modo os direitos sexuais de crianças e adolescentes e os direitos reprodutivos dos adolescentes (não) estão sendo garantidos no âmbito de instituições de atendimento que lidam com este público. Por meio de um estudo preliminar, traremos algumas situaçóes vivenciadas em duas pesquisas de campo que serão desencadeadoras de reflexóes acerca dos avanços e entraves na garantia dos direitos sexuais. 


\section{Sexo, sexualidade e direitos sexuais: algumas definiçóes}

Antes de apresentar as situaçóes selecionadas que servirão de base para a análise e reflexão sobre os direitos sexuais de crianças e adolescentes, convém nos determos em algumas conceituaçôes preliminares. A dificuldade de compreender as distinçóes entre sexo, sexualidade e direitos sexuais endossa o projeto negativista (baseado tão somente nas violaçôes) que rondam os direitos sexuais de crianças e adolescentes. Parte-se, neste artigo, do pressuposto de que, ainda que estes elementos (sexo, sexualidade e direitos sexuais) apresentem certa proximidade e semelhança conceitual, são dotados de particularidades que devem ser explicitadas.

Segundo Laqueur (2001), o sexo, ainda que se refira a um estado corporal, anatômico dos corpos, é uma criação. Para o autor, sexo não é apenas definido por uma biologia neutra e impermeável ao ambiente, não é, portanto, pré-discursivo. O modelo de dois sexos que vigora atualmente data do século XVIII, visto que, até entâo, o discurso científico que imperava era o do modelo grego do sexo úni$c o$, em que se considerava que homens e mulheres compartilhavam um mesmo tipo de aparelho sexual, com capacidades funcionais distintas. A partir do século XVIII, a concepçáo de diferença sexual ancorada na biologia dos corpos emerge impulsionada tanto por avanços científicos como por acontecimentos político-sociais ocorridos, em especial, pelo reposicionamento da mulher na dinâmica social (Laqueur, 2001). Na esteira das reflexôes deste autor, Butler (2003) também desconstrói o corpo/sexo como sendo natural, afirmando que natureza e cultura não se polarizam, mas são complementares, sendo o sexo, portanto, também discursivo. Em resumo, estes autores compreendem o sexo como um elemento corporal, gramatizado por questóes da ordem cultural, ou seja, seus contornos e erogenizações são também construçóes, produto de expectativas engendradas por mecanismos de saber/poder.

Inversamente, a sexualidade não se refere apenas a atributos corporais, sendo o sexo um dos elementos que a compóem, não se restringindo ao exercício sexual genital stricto sensu. Neste trabalho, compreende-se que a sexualidade não se resume a um instinto sexual inerente que nos constitui, mas como um dispositivo datado e não uma prática humana-histórica, coerente e autoevidente (Foucault, 1988). A sexualidade refere-se a um dos âmbitos que compóe a subjetividade e que se conecta náo apenas ao prazer, mas a outros elementos, como a afetividade, a autonomia, a liberdade (e que não se restringe aos fins reprodutivos). Ora, se partirmos desta ótica, a sexualidade passa a ser considerada como uma instância da vida humana que é construída culturalmente, respondendo aos anseios sociais que são desenhados de acordo com as expectativas endereçadas aos indivíduos. 
Podemos verificar que a visão corrente que não permite indissociar genitalidade e sexualidade alimenta o "pânico moral" que ronda crianças e adolescentes em relação à segunda, fazendo com que o comportamento sexual genital seja considerado a única via possível de relaçáo destes sujeitos com sua sexualidade. Os direitos sexuais compóem outro quadro problemático desta tríade conceitual e merece ser analisado no próximo tópico.

\section{O que sáo os direitos sexuais?}

De acordo com Foucault (1988), em meados da era vitoriana há um movimento de silenciamento ao redor das questóes referentes à sexualidade, compreendida como um segredo destinado à vida adulta e familiar. Neste sentido, as práticas sexuais, que circulavam nos espaços públicos, envolvendo a presença de jovens e crianças, são resguardadas entre as paredes do universo privado dos lares. Este movimento auxiliou na construção do imaginário que concebe a sexualidade como questão íntima, da vida privada. Entretanto, com a emersão após a II Guerra Mundial do discurso dos direitos humanos, surge a necessidade de mapear os elementos essenciais que constituem o humano para poder garanti-los politicamente. Vejamos como a sexualidade passa à agenda política dos direitos.

A década de 90 do século passado apresenta avanços substanciais no que se refere à garantia política dos direitos sexuais e reprodutivos, em especial, a partir das discussóes realizadas na Conferência Internacional sobre População e Desenvolvimento (CIPD), que aconteceu em 1993, no Cairo, e a Conferência Mundial sobre a Mulher, em 1995, em Beijim. Na CIPD, o campo do planejamento familiar é revisto e transplantado ao âmbito dos direitos (direitos reprodutivos), sendo que nesta conferência a sexualidade passa a ser considerada como dimensão fundamental da existência humana, garantindo-se no texto final os direitos reprodutivos. Na Conferência de Beijim, os direitos sexuais passam a ser considerados como direitos humanos e não são considerados subjugados aos direitos reprodutivos e nem atrelados unicamente à saúde sexual, ainda que esta o constitua (Arilha, 1999; Corrêa, Januzzi \& Alves, 2003; Pechesky, 1999).

Concomitante aos avanços ocorridos nestas conferências, não poderíamos negligenciar a importante contribuição dos movimentos sociais na garantia política dos direitos sexuais. Esta bandeira surge dos movimentos de gays e lésbicas na década de 90 do século passado, juntamente com o movimento feminista, compreendendo a sexualidade atrelada ao prazer, liberdade e bem-estar sexual no 
âmbito dos direitos humanos (Corrêa et al., 2003). Rios (2006) conceitualiza os direitos sexuais:

Direito à liberdade sexual; direito à autonomia sexual, integridade sexual e à segurança do corpo sexual; direito à privacidade sexual; direito ao prazer sexual; direito à expressão sexual; direito à associação sexual; direito às escolhas reprodutivas livres e responsáveis; direito à informação sexual livre de discriminaçóes. Estes são alguns dos desdobramentos mais importantes dos princípios fundamentais da igualdade e da liberdade que regem um direito da sexualidade. Liberdade, privacidade, autonomia e segurança, por sua vez, são princípios fundamentais que se conectam de modo direto ao direito à vida e ao direito a não sofrer exploração sexual (Rios, 2006, p. 17).

Ainda que em nosso país (Ministério da Saúde, 2006), as políticas dos direitos humanos garantam a vivência plena da sexualidade independente do quesito etário, devemos problematizar que, na prática, crianças e nem mesmo adolescentes são efetivamente contemplados por estes direitos, em especial porque há uma incompreensão compartilhada socialmente que associa direitos sexuais à violação sexual. Ou seja, compreendem-se os direitos sexuais como sinônimo de combate ao abuso, exploração e violência sexual, algo a ser erradicado do universo infanto-juvenil, e perde-se a dimensão do que deve ser afirmado, dos sentidos e desdobramentos que oxigenam o encontro sexual, das tensóes e negociaçóes entre corpos e trocas subjetivas. Náo obstante, convém destacar que o nicho que trata das violaçôes se faz necessário, visto que não há uma relação saudável com a sexualidade quando os limites do outro atravessam e silenciam o nosso próprio; entretanto, ressaltamos a importância de que mais elementos façam parte efetivamente da garantia dos direitos sexuais.

Leite (2009) constata que a temática da sexualidade não está na agenda dos projetos educacionais e assistenciais voltados a crianças e adolescentes e, quando o tema aparece, é numa perspectiva negativa, vinculada a supostos "problemas" como a gravidez "indesejada", às doenças sexualmente transmissíveis/AIDS e à violência. A mesma autora acrescenta que "a sexualidade é abordada quase sempre na perspectiva de risco e náo na do direito" (Leite, 2009, p. 15).

Com a promulgação do ECA (Estatuto da Criança e do Adolescente), crianças e adolescentes saem do registro da menoridade tutelada vigente até então e passam a serem considerados como sujeitos de direitos (Leite, 2009). Entretanto, com a internacionalização dos direitos sexuais, seriam crianças e adolescen- 
tes titulares de todos os direitos, inclusive os sexuais? O paradigma da proteção integral preconizado pelo Estatuto priorizaria a afirmação destes direitos como direitos de cidadania? Quais os limites entre proteção/tutela e autonomia?

De acordo com Melo (2008), são espinhosas as relaçóes entre direito, sexualidade e infância/adolescência visto que, na realidade brasileira, apenas o viés da violação sexual encontra-se em debate. Segundo o autor, há que se atentar para tal fato, uma vez que não se pode criar um direito à proteção suprimindo outro direito, o sexual, pois quando se protege pode-se, por outro lado, retirar a autonomia que deve ser assegurada quando tratamos de direitos sexuais. $\mathrm{O}$ autor traz a reflexão de que a idade não deve ser preditor único para se criar políticas para as crianças/adolescentes, é quesito que deve ser tomado como um fator importante, mas não central. Esta afirmação está baseada no artigo $2^{\circ}$ da Convenção sobre Direitos da Criança (ONU, 1989):

c) distinçóes com base na idade devem prover parâmetros previsíveis e objetivos, mas devem ser considerados apenas como um ponto de partida para análise, porque crianças e adolescentes desenvolvem-se de maneiras distintas e a idade é apenas uma reflexão aproximativa do desenvolvimento de suas capacidades.

Tendo em consideração os intensos debates acerca dos direitos sexuais de crianças e adolescentes e a importância do aprofundamento conceitual para avançarmos neste sentido, passemos adiante à análise de algumas situaçóes ocorridas em duas pesquisas de campo realizadas com crianças e adolescentes de contextos distintos. Com esta metodologia, analisaremos os modos como a sexualidade aparece no cotidiano destes sujeitos e como a temática é recebida pelas instituiçóes em questão. Pretendemos com estes excertos avaliar de que modo situações localizadas podem nos fornecer pistas, ser metáforas de uma discussão mais ampla, que aponta para a tensa relação entre sexualidade, experiência infanto-juvenil e direitos sexuais e reprodutivos.

\section{Crianças e sexualidade: conjugando o verbo prexecar}

A primeira pesquisa ${ }^{1}$ que vamos apresentar teve como lócus uma Unidade Pública de Educação Infantil localizada em um subúrbio do município de Rondonópolis $/ \mathrm{MT}^{2}$, com crianças entre cinco a seis anos de idade ${ }^{3}$. Os encontros ocorreram semanalmente ao longo dos anos 2005 e 2006 com turmas diferentes, 
respeitando a faixa etária acima definida. Foram realizadas observaçóes-participantes do cotidiano escolar e entrevistas com as crianças (áudio e videogravadas) 4 . O estudo em questão teve por objetivo principal a investigação das experiências lúdicas das crianças na tentativa de compreender que sentidos são construídos acerca de tais vivências.

$\mathrm{Na}$ pesquisa em questão, a sexualidade apresentou-se como tema recorrente entre um grupo de crianças. Estas apresentavam saberes e discursos bastante elaborados acerca da sexualidade, mas compreendiam ser um tema delicado e proibido a elas. Portanto, as brincadeiras que envolviam a temática ocorriam em espaços não-públicos, propícios àquelas desautorizadas. Durante a observaçáo de algumas crianças brincando debaixo de uma mesa, surgem os seguintes discursos.

Três meninas manipulam bonecas da Barbie, cochicham, riem e olham para os lados, na tentativa de garantir que nenhum adulto, que não os pesquisadores, se aproxime:

Bruna ${ }^{5}$ : Eu vi uma mulher sentada em cima de uma mulher e eu vi a mulher em cima da cadeira namorando com uma mulher.

Pesquisadora: Você viu uma mulher namorando uma mulher, na cadeira? Como você viu? Onde você viu, Bruna?

Bruna: Na televisão.

Pesquisadora: Na televisão? Lá na sua casa? Que horas você viu na televisão?

Bruna: Ela prexecou.

$[\ldots]$

Ana: A minha mãe também deixou eu ver. Eu vi a mulher "prexecando" em cima da mulher.

Pesquisadora: É?

Ana: O homem tirou o pinto, e a mulher tirou a "prexeca" e colocou no homem ${ }^{6}$.

Joana: Nós vimos pelado (Diário de campo).

A brincadeira de prexecar, que ocorria com bonecas Barbies e Ken ${ }^{7}$, não acontecia na presença da educadora e era circunscrito a um grupo de meninas que detinha a "patente" sobre a brincadeira. Falar sobre sexo é um "passaporte" essas crianças possuíam, pois, além de confrontar a imagem idealizada que possuem, lhes possibilitava transitar, ainda que no registro simbólico e da fantasia, pelo inacessível mundo adulto (Salgado, Carvalho \& Rodrigues, 2009). A brincadeira, portanto, inscrevia essas crianças em outro registro que não aquele român- 
tico que aparta seus mundos destes saberes considerados subversivos, e a detenção de tais códigos e informaçóes as fazia ter um prestígio no grupo de crianças.

Em relação à brincadeira apresentada anteriormente, é importante ressaltar a postura adotada pela instituição de ensino. A professora responsável pela turma, ainda que soubesse das brincadeiras que envolviam o conteúdo sexual, compartilhava o fato com os pesquisadores e não as proibia, mas tentava fazer com que as crianças se interessassem por outros temas, ou seja, buscava desvirtuar sua atenção por compreender que tais brincadeiras não lhes eram apropriadas. Já outras instâncias da instituição agiram de modo controverso à postura da professora. Num encontro entre pesquisadores e as crianças, Bruna, principal responsável pelas brincadeiras "não-autorizadas", faz uma reclamação. A mesa, que até então servia de esconderijo para as brincadeiras mais reservadas, como o "prexecar", além do boneco Ken haviam sido retirados da sala de aula. Conversando com a educadora, averiguamos que esta foi a estratégia utilizada pela instituição que, ao tomar ciência das brincadeiras, tentou garantir que apenas outras interaçóes lúdicas, que não as que envolviam o tema da sexualidade, ocorressem, projeto que poderia ser garantido a partir da ausência de tais objetos. Entretanto, para a surpresa dos pesquisadores, em seguida as crianças voltaram a brincar de "prexecar" num canto da sala de aula, agora com duas bonecas Barbies, criando táticas que (re)semantizaram o espaço e as regras (Certeau, 1996).

A situação acima nos remete à Foucault (1988), que descreve que após a era vitoriana o sexo, que até então fazia parte da rotina de crianças, lhes é apartado e passa a ser considerado natural e exclusivamente da vida adulta (a infância torna-se assexuada). Entretanto, para que se pudesse garantir a pureza do universo infantil, uma verdadeira maquinaria de controle foi disseminada no sentido de expurgar a sexualidade dos discursos e práticas das crianças, uma verdadeira perseguição à sexualidade infantil "invisível e presente": "As crianças, por exemplo, sabe-se muito bem que não têm sexo: boa razão para interditá-lo, razão para proibi-las de falarem dele, razão para fecharem os olhos e tapar os ouvidos onde quer que venham a manifestá-lo, razão para impor um silêncio geral e aplicado" (Foucault, 1988, p. 10).

Podemos analisar que a postura institucional parte do pressuposto da criança como ícone da pureza, de uma inocência que deve ser preservada a todo custo. Entretanto, a instituição não concebe que interaçóes lúdicas são alimentadas por códigos culturais mais amplos, e a retirada dos objetos, sem a devida problematização das brincadeiras e discursos, não avança num questionamento sobre, por exemplo, como as crianças se subjetivam a partir dos saberes que manipulam, metas de um projeto educativo integral. 
É preciso também destacar que, com a análise aqui empreendida, não pretendemos moralizar a conduta da instituiçáo educativa, julgando-a desatrelada de um contexto social maior do qual fazem parte também os pais e a sociedade, que anseiam que a instituição educativa higienize o universo infantil de elementos que firam a inocência. Por outro lado, devemos analisar quais os efeitos e o que se produziu com o silêncio da instituiçâo frente às brincadeiras e o autoritarismo da retirada dos objetos. Há, portanto, uma recusa coletiva da sexualidade infantil, visto que o seu reconhecimento implica em ter que lidar com o que se nega, construir subsídios e elementos que não se encontram acabados no campo social, mas que devem ser construídos conjuntamente, nas situaçóes concretas do dia-a-dia.

Tendo em consideração o que conceituamos como direitos sexuais anteriormente, tais direitos estariam sendo garantidos com a postura da instituição? Cabe ressaltar que falar em direitos sexuais de crianças implica tratar de um campo espinhoso, visto que discursos conservadores entendem que os direitos sexuais referem-se à conivência e incitação das práticas sexuais de crianças. Entretanto, esta parece ser uma compreensão equivocada que, mais uma vez, confunde sexualidade e genitalidade. As mesmas crianças do excerto acima, ao serem interpeladas se brincavam de "prexecar", respondiam unanimemente que eram brincadeiras que "só os bonecos podiam", que eram "coisas de adultos" e que "criança não pode fazer". As crianças, portanto, dentre outras possíveis leituras, parecem compreender alguns limites que delimitam infância e idade adulta, mas polemizam a rigidez destas barreiras ao demonstrar que também a sexualidade faz parte de seus universos, ainda que de modo reconfigurado.

O exemplo é alusivo à necessidade de pensar os direitos sexuais de crianças, em primeiro plano, como um direito ao saber e à liberdade de manusear informaçôes, dúvidas e brincadeiras diversas, mesmo que sejam consideradas impróprias ao universo infantil. Em contraponto, parece caber também aos direitos sexuais de crianças a presença ativa de um adulto que polemize e problematize criticamente os assuntos surgidos, garantindo a autonomia das brincadeiras e discursos, ainda que sob a égide da tutela no que se refere às violaçôes.

\section{Experiências adolescentes: encontro entre direitos sexuais e reprodutivos}

A segunda investigação ${ }^{9}$ foi realizada, junto a duas instituiçôes públicas de saúde da cidade do Rio de Janeiro ${ }^{10}$, com adolescentes grávidas entre treze e 
dezoito anos de idade ${ }^{11}$. Neste estudo, foram entrevistadas trinta e duas adolescentes. Estas entrevistas foram audiogravadas e transcritas para posterior análise. A pesquisa em questão privilegiou a escuta das adolescentes com o objetivo de conhecer, a partir de seus depoimentos, os modos como as meninas vivenciam a maternidade no momento da gravidez.

Como apontado anteriormente, os estudos em torno da sexualidade adolescente concentram suas abordagens nos riscos potenciais das experiências sexuais vinculadas ao "problema" da gravidez na adolescência e/ou de doenças. Tal constatação, apresentada no trabalho de Leite (2009), sinaliza para a necessidade de uma reflexão acerca da sexualidade adolescente na perspectiva dos direitos sexuais como experiências de vida. Neste cenário, problematizar a tensão entre autonomia e tutela se apresenta como um dos desafios importantes a serem enfrentados para a definição do que se pretende alcançar quando se fala sobre direitos sexuais de adolescentes.

Os estudos em torno da gravidez na adolescência, em especial aqueles que se aproximam do modelo biomédico, reforçam a visão da maternidade na adolescência como um problema, sendo a gravidez, genericamente, classificada como um evento de risco para a saúde da mãe e de seu filho (Brandão, 2006; Heilborn, 2006). Por sua vez, o discurso psicológico vem reforçar a noção de "imaturidade psicológica”, o que promove a atualização da imagem da gravidez como sendo indesejada e que, portanto, deve ser evitada. Com isso, não pretendemos invalidar as implicações médicas e psicológicas de uma gestação no período da adolescência, mas destacar a necessidade de refletirmos sobre os efeitos de tais discursos no cotidiano das práticas sociais, criando uma representação única sobre a gravidez na adolescência. Nosso interesse é ampliar este debate, incluindo os diversos sentidos que esta experiência provoca na vida das próprias adolescentes, uma vez que é necessário discutir a gravidez articulada com o exercício da sexualidade neste período da vida.

\section{Gravidez na adolescência: um acontecimento indesejado ou um desejo planejado?}

É comum a descrição da gravidez de jovens na faixa de 15 a 19 anos como "precoce", “indesejada” ou "não planejada”. Tal compreensão assume que este período não seria apropriado, tanto em termos sociais quanto biológicos, para gestação. Entretanto, ao mergulharmos no universo de sentidos atribuídos à gravidez pelas adolescentes que participaram da pesquisa, encontramos depoi- 
mentos que apontam para a possibilidade da gravidez ser uma decisão das jovens pela maternidade:

Elisa (18 anos): Pra mim está sendo legal porque eu planejei com o meu esposo, náo foi por acaso, foi uma coisa que tanto ele queria, quanto eu. Já tem dois anos que a gente mora junto [...] agora resolvermos ter, fomos ao meu ginecologista e conversamos, eu parei de tomar remédio e um mês depois eu engravidei (Silva, 2011).

Beatriz (17 anos): Eu sendo adolescente ou não eu sempre quis engravidar, há dois anos que eu tentava engravidar e não conseguia até que um dia eu engravidei, nunca tomei anticoncepcional, por isso eu achava que não podia engravidar, mas foi um planejamento, eu vivia minha vida, por isso que eu saí de casa com 13 anos e fui viver a minha vida, tenho cinco anos com meu esposo, estou grávida, mas não foi uma coisa que me deixou abalada, foi uma coisa que eu queria pra mim, tem muitas adolescentes que náo querem, abortam, não é uma coisa planejada, no meu caso é diferente, a minha gravidez não está me dificultando nem me afetando em nada (Silva, 2011).

Considerar que a gravidez na adolescência pode também se configurar como a realização de um projeto de vida significa um avanço em relação ao debate sobre o tema. Com frequência, este tema ganha destaque na mídia, porém apresentando os riscos físicos e psíquicos dessa experiência, além dos prejuízos sociais para a jovem mãe, centrados no afastamento da vida escolar e no abandono de projetos futuros. Raramente se focalizam estas experiências sob a perspectiva do desejo de maternidade e paternidade, situaçóes em que os(as) adolescentes voluntariamente escolheram e decidiram por ter filhos. Estar aberto à escuta destes depoimentos e compreender a especificidade de cada situação é um caminho para enfrentarmos a tensão inerente ao debate sobre autonomia e tutela, além de admitir ser necessário reconhecer o exercício responsável da sexualidade como um direito dos jovens.

Vale mencionar que a maternidade ganha contornos diferenciados em classes sociais distintas. Nas classes economicamente mais favorecidas, observamos a valorização da formação acadêmica e profissional, sendo a maternidade e a constituição da família projetos que devem ser adiados, uma vez que podem comprometer a futura inserção no mercado de trabalho e a consequente aquisição de autonomia financeira. Nas classes populares, a trajetória escolar e, consequentemente, a profissional não ocorrem, necessariamente, de modo tão garantido. A realidade deste contexto "exige" que os/as jovens deste segmento obtenham autonomia mais cedo, buscando inserção no mercado de trabalho para contribuir 
com o orçamento familiar, sobretudo no caso dos meninos (Cabral, 2005). As meninas, muitas vezes, são responsáveis pelo cuidado da casa e dos irmãos mais novos, cooperando para que o pai e/ou a mãe possam trabalhar.

Tatiana (16 anos): Eu tenho três irmãos, quando eles eram pequenos eu ajudava a minha mãe a cuidar deles aí pra mim vai ser mais fácil cuidar da criança, mas agora a responsabilidade é toda minha, porque antigamente eu só ajudava a minha mãe e agora a minha mãe que vai me ajudar (Silva, 2011).

Rafaela (18 anos): Eu tinha vontade de ser mãe desde os meus 10 anos de idade, quando a minha mãe teve o meu irmão, eu cuidava dele como se fosse meu filho, eu cismei que queria ser mãe e depois esqueci, agora quando eu menos pensei em ser... (Silva, 2011).

Estas narrativas nos permitem pensar que desempenhar os papéis de esposa e mãe pode se configurar como uma trajetória "natural", em função da inserção dessas jovens num ambiente que, de certo modo, limita seus projetos de escolaridade e qualificação profissional. Brandão (2006) argumenta que a gravidez na adolescência pode se configurar como um reconhecimento social - um projeto de vida - garantia de conquista de status social frente às dificuldades destas jovens de se inserirem como mulheres em outros espaços valorizados pela sociedade.

Outro aspecto que se destacou nos depoimentos das adolescentes entrevistadas é o reconhecimento da gravidez como uma espécie de "rito de passagem" para a vida adulta. Neste sentido, observamos que as jovens consideram que a gravidez trouxe uma "nova" percepção de si, permitindo que se sentissem mais responsáveis, maduras e centradas. A maternidade para elas pode representar um "abalo" positivo, trazendo um novo sentido para suas vidas e impulsionando a realização de projetos futuros.

Roberta, (17 anos): Eu me olho e vejo que eu amadureci mesmo, por isso eu falo pra você que são mais pontos positivos do que negativos, minha mãe percebe isso, e meu pai também vê que pra mim foi bom. [...] O momento não era, mas aconteceu, foi bom, foi muito bom, eu acho que era isso que eu estava precisando pra acordar de vez, foi mais um incentivo porque eu estava muito desligada, eu ia pro colégio porque tinha que estudar, minha mãe nunca reclamou de nota, porque eu sempre tiro nota boa, agora é mais um incentivo eu tenho que estudar porque agora eu tenho meu bebezinho (Silva, 2011). 
A gravidez pode ser vista ainda como a possibilidade de construir uma família diferente da família que tiveram.

Beatriz (17 anos): É uma experiência de vida, o que ela (se referindo à mãe) não foi pra mim eu quero ser para os meus filhos [...] eu quero ter a minha família, o que eu não tive eu quero ter, eu quero construir isso, tem muita garota que só quer curtir a vida, indo pro baile, deixando o filho com a avó, e não é assim que eu penso, eu quero casar, já estou resolvendo a papelada e ter o meu filho (Silva, 2011).

A maioria das pesquisas sobre o tema da gravidez na adolescência, especialmente na área da saúde pública, parte do pressuposto de que a adolescência é uma etapa universal do desenvolvimento humano. Para Stern e García ${ }^{12}$ (1999), estes estudos desconsideram as diferenças sociais que marcam as etapas da vida e as diversas implicaçóes que a gravidez pode ter sobre as trajetórias das jovens, bem como sobre suas redes sociais. Os autores criticam o uso do fator etário como elemento privilegiado de análise, pois este viés obscurece as possibilidades concretas de "escolha" para as jovens de diferentes classes sociais. O que queremos destacar é o cuidado com análises generalistas que não contribuem para uma compreensão do tema e seus diversos significados, inclusive de poder simbólico, como bem refletem Catharino e Giffen (2002):

Não se trata aqui, de fazer a condenação ou o elogio da gravidez na adolescência. Trata-se, sim, de trazer à cena uma realidade que, sem negligenciar os perfis epidemiológicos, nos remetem a histórias: trajetórias que contêm sonhos, esperanças, dores, desilusóes e que permitem às meninas se apropriarem das adversidades, para transformar - mesmo que ilusoriamente - o seu cotidiano em algo que valha a pena ser vivido. Ser mãe para estas meninas talvez seja uma das poucas formas que lhes restam, no sentido de se colocarem no mundo como sujeitos sociais (Catharino \& Giffen, p. 7).

\section{Desafio: da proteçấo à conquista de autonomia}

A discussão sobre autonomia e tutela veio à tona em diversos momentos da pesquisa. Inicialmente ela surgiu relacionada à obtenção da assinatura pelo responsável, no caso das menores de 18 anos, do termo de consentimento livre 
e esclarecido. Se, por um lado, compreendemos que a exigência desta assinatura pelos comitês de ética em pesquisa se justifica como garantia contra abusos e usos indevidos, por outro lado essa cobrança revela uma ambivalência da própria condição em que se encontram as adolescentes grávidas: não são legalmente autorizadas para falar sobre si mesmas, mas estão prestes a tornarem-se responsáveis por seus filhos.

Jobim e Souza (2010) reflete sobre este tema sinalizando a necessidade de problematizarmos as consequências desta atitude protecionista em termos políticos. Sem negar a importância dos avanços históricos frente ao dever do Estado em garantir os direitos da criança e do adolescente, a autora argumenta que o discurso da proteção cria uma condição de dependência e de incapacidade sociopolítica da criança e do adolescente.

Durante o percurso da pesquisa, o tema da autonomia também surgiu no discurso de uma profissional da área de saúde responsável pelo atendimento médico das adolescentes. Ao expor a ela a exigência de obter autorização dos responsáveis para que as meninas pudessem participar da pesquisa, a profissional fez o seguinte relato: "Se uma menina vem para uma consulta e pede para que eu receite um anticoncepcional a ela, eu não vou pedir autorização dos pais para fazer isso. No seu trabalho elas não irão se submeter a nenhum experimento, irão falar somente o que quiserem" (Diário de campo, 09/10/2010).

Este tema também retornou no relato de uma das entrevistadas, desta vez relacionado ao modo como os serviços de saúde têm lidado com esta questão.

Adriana (16 anos): Foi como na primeira consulta, era para começar num dia e não consegui começar porque não estava com meu responsável. Eu pensei, eu estava com o meu responsável na hora de fazer? Sem cabimento, me falaram: "a gente não vai ter como abrir seu prontuário", nem quis argumentar porque pelo ECA é um direito nosso a gente ser atendido sozinho. E se meus pais não soubessem? O sigilo é meu. Me responderam que não podia iniciar sem terem certeza que meus pais sabiam. E daí? E se eu estivesse passando mal, só porque não estou com meu responsável eu não poderia ser atendida, mas não quis nem argumentar porque minha cabeça estava táo cheia. Vim depois e trouxe o meu pai, e o que meu pai veio fazer aqui? Nada, porque meu pai trabalha de noite, de manhã é o horário que ele chega e vai dormir, então meu pai estava aqui dormindo, eu achei aquilo totalmente desnecessário, pra 
que eu preciso de meu pai aqui, somente para que vissem que ele estava aqui? (Silva, 2011).

O que se percebe a partir dos depoimentos das jovens é a reivindicação do direito a ter autonomia para participar da decisão sobre questōes que dizem respeito ao seu corpo, à sua vida. Neste caso, não estamos defendendo a ausência da responsabilidade do adulto frente às demandas dos adolescentes, mas o respeito do adulto em relação à singularidade da experiência do jovem e o seu direito de ser responsável em primeira instância por decisóes que afetam sua vida diretamente. Entendemos que o discurso da proteçáo deve evoluir para o dever ético de considerar o adolescente como sujeito de direitos e que o papel do adulto deve ser o de apoiar e orientar os jovens em suas escolhas responsáveis.

\section{Consideraçóes finais}

Em primeiro plano, há que problematizarmos que pensar em direitos sexuais de crianças e adolescentes como algo dado a priori, circunscrevendo-se os limites entre autonomia e proteção, não é caminho profícuo para se pensar nas garantias de cidadania que pretendemos neste texto. Há que pensarmos em direitos sexuais que são circunstanciais, construídos na negociação entre crianças e adultos, de acordo com o contexto dos signos e vivências de cada cultura e subcultura específicas, pois, se assim não o for, poderemos estabelecer uma visão monocromática para o universo infanto-juvenil e seus direitos. A autonomia sexual deve ser compreendida como um processo que ocorre no cotidiano, portanto deve ser tecida a partir de dois fios condutores principais: da proteçấo e da liberdade. Desta feita, cabe ao outro, adultos e instituiçóes que lidam com este público, não se omitir da pluralidade de ser de crianças e adolescentes (que são constituídos por sexualidades específicas, em contextos situados), fundamentando relaçóes não pautadas meramente em mecanismos disciplinadores e moralizantes, mas numa prática implicada e crítica dos saberes e experiências que dizem respeito ao escopo sexual.

De acordo com Rios (2006), há que garantirmos um direito democrático da sexualidade, que se refere à possibilidade da livre relação responsável com a dimensão sexual, ao perspectivar que tal direito deve ser compreendido em igualdade com todos os outros, visto que não há hierarquias entre os direitos, mas uma transversalidade. Segundo Melo (2008), para que este projeto seja efetivado 
e garantido, é necessário avançar na discussão entre controle da sexualidade e autonomização, posto que,

a partir da afirmação da subjetividade jurídica de crianças e adolescentes e a reflexão sobre os novos espaços sociais abertos à infância e à juventude, abrimo-nos ao desafio de pensar no campo da sexualidade, os termos da cidadania de crianças e adolescentes pela afirmação de seu direito ao desenvolvimento sob o marco dos direitos humanos, numa renovada tentativa de fundamentação da justiça (Melo, 2008, p. 18).

Não obstante, à mão dos argumentos acima, avaliamos ser de vital importância o aprofundamento conceitual acerca dos direitos sexuais de crianças e adolescentes de modo que ofereçamos subsídios ao campo jurídico e possamos abrir caminho à cidadania infanto-juvenil de modo mais integral. Entretanto, consideramos que, para a efetivação deste avanço, é necessário que crianças e adolescentes sejam envolvidos neste processo e que seus discursos e práticas ganhem materialidade efetiva na construção dos saberes endereçados a estes sujeitos de direitos.

\section{Referências}

Ariès, P. (1981). História social da criança e da familia. 2. ed. Rio de Janeiro: Guanabara. Arilha, M. (1999). Masculinidades e gênero: discursos sobre responsabilidade na reprodução. (Dissertação apresentada ao Programa de Mestrado em Psicologia Social da Pontifícia Universidade de São Paulo, São Paulo, SP).

Bakhtin, M. (2003). Estética da criação verbal. São Paulo: Martins Fontes.

Brandão, E. R. (2006). Gravidez na adolescência: um balanço bibliográfico. In: M. L. Heilborn, M. L., Aquino, M. L., Bozon, M. \& Knauth, D. R. (orgs.). O aprendizado da sexualidade: reprodução e trajetórias sociais de jovens brasileiros (pp. 61-95). Rio de Janeiro: Fiocruz e Garamond.

Butler, J. (2003). Problemas de gênero: feminismo e subversão da identidade. Rio de Janeiro: Civilização Brasileira.

Cabral, C. S. (2005). Gravidez na adolescência: negociaçóes na família. In: M. L. Heilborn, L. F. D. Duarte, C. E. Peixoto \& M. Lins de Barros (orgs.). Sexualidade, família e ethos religioso (pp. 175-197). Rio de Janeiro. Garamond.

Catharino, T. R. \& Giffen, K. (2002, novembro). Gravidez e adolescência: investigação de um problema moderno. In: XIII Encontro da Associação Brasileira de Estudos Populacionais, Ouro Preto. 
Certeau, M. (1996). A invenção do cotidiano: artes de fazer. Petrópolis: Vozes.

Cornwall, A. \& Jolly, S. (orgs.). (2008). Questöes de sexualidade: ensaios transculturais. Trad. Jones de Freitas. Rio de Janeiro: Abia.

Corrêa, S., Januzzi, P. M. \& Alves, J. E. D. (2003). Direitos e saúde sexual e reprodutiva: marco teórico-conceitual e sistema de indicadores. In: S. Cavenaghi (coord.). Indicadores municipais de saúde sexual e reprodutiva (pp. 14-26). Rio de Janeiro: ABEP.

Estatuto da Criança e do Adolescente (1990). Disponível em <http://www.planalto.gov.br/ccivil_03/leis/L8069.htm>. Recuperado em 30 de setembro de 2011.

Foucault, M. (1988). História da Sexualidade 1: a vontade de saber. 6. ed., vol. 1. Rio de Janeiro: Graal.

Foucault, M. (2001). Os anormais. São Paulo: Martins Fontes.

Heilborn, M. L. (2006). Experiência da sexualidade, reprodução e trajetória biográficas juvenis. In: M. L. Heilborn; E. M. L. Aquino; M. Bozon \& D. R. Knauth. O aprendizado da sexualidade: reprodução e trajetórias sociais de jovens brasileiros (pp. 30-59). Rio de Janeiro: Fiocruz e Garamond.

Jobim e Souza, S. (2010). Criança e adolescente: construção histórica e social nas concepçóes de proteção, direitos e participação. In: M. A. Ungaretti. Criança e adolescente. Direitos e sexualidade (pp. 87-100). São Paulo: Associação Brasileira de Magistrados, Promotores de Justiça e Defensores Públicos da Infância e Adolescência - ABMP.

Laqueur, T. (2001). Inventando o sexo: corpo e gênero dos gregos a Freud. Rio de Janeiro: Relume Dumará.

Leite, V. J. (2009). Sexualidade adolescente como direito? A visão de formuladores de políticas públicas. (Dissertação de mestrado do Instituto de Medicina Social. Universidade do Estado do Rio de Janeiro Rio de Janeiro, RJ).

Melo, E. R. (2008). Direito e norma no campo da sexualidade na infância e na adolescência. In: M. A. Ungaretti. Criança e adolescente. Direitos e sexualidade (pp. 43-60). São Paulo: Associação Brasileira de Magistrados, Promotores de Justiça e Defensores Públicos da Infância e Adolescência - ABMP.

Ministério da Saúde (2006). Direitos sexuais, direitos reprodutivos e métodos anticoncepcionais. Brasília: Secretaria de Atenção à Saúde (Departamento de Açóes Programáticas Estratégicas).

ONU (1989). Convenção sobre os Direitos da Criança. Disponível em <http://www.onu-brasil.org.br/documentos_convencoes.php $>$. Recuperado em 14 de setembro de 2010.

Pecheski, R. (1999). Direitos sexuais um novo conceito a prática política internacional. In: R. Parker \& R. M. Barbosa (orgs.). Sexualidades pelo avesso: direitos, identidades e poder. Rio de Janeiro: IMS/UERJ.

Rios, R. R. (2006). Para um direto democrático da sexualidade. Horiz. antropol., 12, 71-100. 
Salgado, R. G., Carvalho, C. de S. \& Rodrigues, M. A. C. (2009). Quando as meninas brincam de ser mulher: reflexóes sobre mídia, cultura lúdica, gênero e sexualidade. In: M. C. P. Passos \& R. M. R. Pereira. Identidades, diversidade: práticas culturais em pesquisa (pp. 43-54). Petrópolis: DP et alii.

Silva, E. R. da. (2011). Mosaico de experiências: construindo sentidos sobre a gravidez na adolescência. (Dissertação de mestrado, Pontifícia Universidade Católica do Rio de Janeiro, Departamento de Psicologia, Rio de Janeiro).

Stern, C. \& García, E. (1999). Hacia un nuevo enfoque en el campo del embarazo adolescente. Reflexiones. Sexualidad, Saludy Reproducción, 13, 71-100.

\section{Notas}

${ }^{1}$ Trata-se de investigaçóes do projeto de pesquisa intitulado: "Infância e Cultura Lúdica Contemporânea: a Criança entre Brinquedos, Narrativas, Saberes e Competências”, sob orientação da Profa. Dra. Raquel Gonçalves Salgado, do Grupo de Pesquisa "Infância, Juventude e Cultura Contemporânea”, da Universidade Federal de Mato Grosso/Rondonópolis. Projeto de pesquisa não publicado.

${ }^{2}$ Localizado a cerca de $212 \mathrm{~km}$ de Cuiabá-MT e que, de acordo com o IBGE, possui uma população em torno de 180 mil habitantes.

${ }^{3}$ A participação das crianças na pesquisa foi consentida pelos seus responsáveis.

${ }^{4}$ As estratégias metodológicas foram construídas a partir das reflexôes teóricas de Bakhtin (2003).

${ }^{5}$ Os nomes utilizados são fictícios.

${ }^{6}$ Nos relatos dessas crianças, "prexecar" designava a relação sexual em que as mulheres "engoliam os homens", sugerindo certo protagonismo feminino no ato sexual.

${ }^{7}$ Parceiro da boneca Barbie.

${ }^{8}$ A palavra "passaporte" é utilizada no sentido de mostrar como determinados grupos de crianças criam espaços reservados de jogos e brincadeiras onde elas definem quem pode ou não participar. Só é permitido entrar no jogo/brincadeira as crianças que apresentam as credenciais culturais, ou seja, o domínio dos códigos ou regras de interação lúdica necessários para o jogo acontecer. Para maiores informaçóes: R. G. Salgado, Ser criança e herói no jogo e na vida: a infância contemporânea, o brincar e os desenhos animados. Tese de Doutorado - Programa de Pós-Graduação, Departamento de Psicologia, Pontifícia Universidade Católica do Rio de Janeiro, 2005.

${ }^{9}$ Trata-se da pesquisa de mestrado intitulada Mosaico de experiências: construindo sentidos sobre a gravidez na adolescência, defendida no Departamento de Psicologia da PUC-Rio, em agosto de 2011, por Elisângela Ribeiro da Silva. 
${ }^{10}$ A pesquisa foi realizada no Hospital Maternidade Oswaldo Nazareth e na Maternidade Escola da UFRJ, com a aprovação dos Comitês de Ética das referidas instituiçóes. As adolescentes eram convidadas a participar da pesquisa no momento da consulta de acompanhamento pré-natal.

${ }^{11}$ A participaçáo das adolescentes menores de 18 anos na pesquisa foi consentida oficialmente pelos seus responsáveis. Vale salientar que a análise aqui apresentada resguardou informaçóes acerca das participantes, tais como nomes e/ou dados que facilitassem o reconhecimento das identidades.

${ }^{12}$ Em tradução das autoras.

Recebido em 27 de outubro de 2011 Aceito para publicação em 13 de março de 2012 